P0068

\title{
OPTICAL PARAMETERS COMPARISON OF DENTISTRY OPERATION LIGHTS
}

\author{
Antonio F G Ferreira Junior
}

DOI 10.25039/x46.2019.PO068

from

CIE x046:2019

Proceedings

of the

29th CIE SESSION

Washington D.C., USA, June 14 - 22, 2019

(DOI 10.25039/x46.2019)

The paper has been presented at the 29th CIE Session, Washington D.C., USA, June 14-22, 2019. It has not been peer-reviewed by CIE.

(c) CIE 2019

All rights reserved. Unless otherwise specified, no part of this publication may be reproduced or utilized in any form or by any means, electronic or mechanical, including photocopying and microfilm, without permission in writing from CIE Central Bureau at the address below. Any mention of organizations or products does not imply endorsement by the CIE.

This paper is made available open access for individual use. However, in all other cases all rights are reserved unless explicit permission is sought from and given by the $\mathrm{CIE}$.

CIE Central Bureau

Babenbergerstrasse 9

A-1010 Vienna

Austria

Tel.: +4317143187

e-mail: ciecb@cie.co.at

www.cie.co.at 


\title{
OPTICAL PARAMETERS COMPARISON OF DENTISTRY OPERATION LIGHTS
}

\author{
Ferreira Junior, A.F.G. ${ }^{1}$ \\ ${ }^{1}$ Institute for Technological Research - IPT, Sao Paulo, BRAZIL \\ agenti@ipt.br
}

DOI 10.25039/x46.2019.PO068

\begin{abstract}
This work presents spectral irradiance distribution, colour rendering index and chromaticity coordinate comparison of dentistry operating lights with LED light source and filament light source and evaluate this parameter according to ISO 9680:2014 requirements. Three different dentistry operation lights were compared where 2 of them use LED source and the other a filament source. The equipment chromaticity results are in agreement to the standard limits. One of LED light source equipment presented a colour rendering index above de standard limit, despite the ISO 9680:2014 excludes LED light source from the general colour rendering index requirement.
\end{abstract}

Keywords: Irradiance, Colour Rendering, Dentistry, Colour

\section{Introduction}

The recent publication of standard ISO 9680:2014 - Dentistry Operation Lights (ISO, 2014) changes the requirements for equipment colour performance according to the type of light source used. In this standard revision, equipment using LED light sources are excluded from colour rendering index $(\mathrm{CRI})$ performance, although other types of light sources are not.

The use CIE colour rendering index (CIE, 1995) for general illumination colour comparison index is well stablished. In the medical field, this is a performance parameter for dentistry operation lights (ISO, 2014) and surgical luminaire (IEC, 2013). However, the CRI capability to correlate colour differences for LED source types was questioned for many works (Sándor et al., 2003; Guo \& Houser, 2004; Sándor \& Schanda, 2006). A CIE Report was published regarding the $C R I$ limitation for generally application in colour rendering rank when white LED sources are used (CIE, 2007).

Although the CIE 177:2007 publication (CIE, 2007) effects could be perceived in the revision of the colour rendering index requirements from dentistry operation lights in the ISO 9680 (ISO, 2014), not all medical application followed its recommendation. The last edition of surgical luminaires standard (IEC, 2013) maintained the CRI performance requirement even for equipment using LED sources.

A recent CIE publication, CIE 224:2017, presents in detail the major reasons for CRI failures in colour rendering rank when LED sources are evaluated (CIE, 2017), which concerns nonuniformity in method spectral sensitivity and colour space adopted to CRI calculation. This CIE publication proposes new colour comparison index, colour fidelity index, to be used in international standardization.

Regarding the impact of colour comparison index in specific application fields, this work presents the colour characterization of dentistry operation lights according to current standardization requirements.

\section{Methods}

To characterized dentistry operation light concerning its colour aspects it is necessary to determine its spectral power distribution. A setup was built for spectral irradiance distribution measurement using a commercial spectroradiometer associated to a spectral irradiance certified reference lamp. The dentistry operation light spectral irradiance measurement 
procedure was performed according to ASTM G138:2012 (ASTM, 2012) and CIE 63:1984 (CIE,1984). And the dentistry operation light configuration was conducted in conformity to ISO 9680:2014 (ISO, 2014).

The base of measurement arrangement was composed of a spectroradiometer model PR-705, manufactured by Photoresearch, and a PTFE (polytetrafluoroethylene) plane diffuser. This base setup was calibrated by a 1000 W FEL-type spectral irradiance certified lamp and a low pressure mercury spectral lamp, using the measurement geometry of $0^{\circ}$ incidence light and $45^{\circ}$ measurement $\left(0^{\circ}: 45^{\circ}\right)$. The figure 1 presents a schematic diagram for the experimental setup.

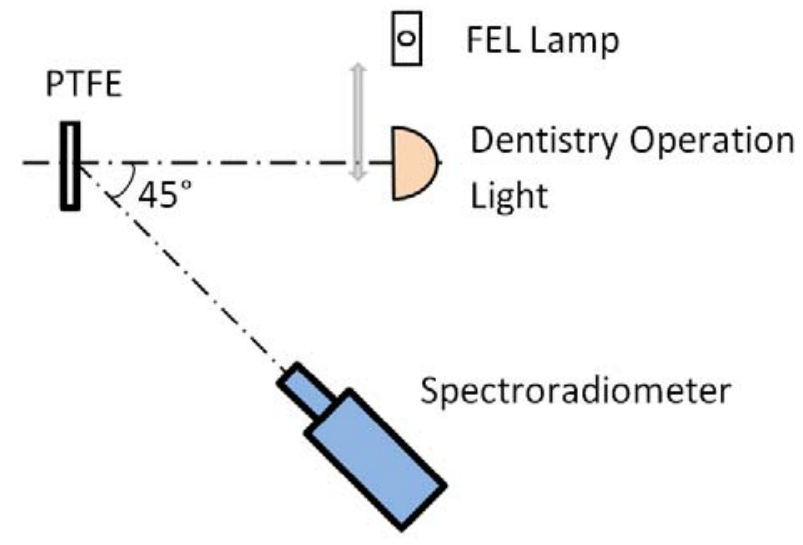

Figure 1 - Caption of Figure 1

The dentistry operation light spectral irradiance was measured at the same geometry used for the system calibration. Its colour rendering index and chromaticity coordinate were calculated from the spectral irradiance measurement using the software included in the publication CIE 13.3:1995 (CIE, 1995). The results of colour calculation were compared to the limits of standard ISO 9680:2014 (ISO, 2014).

\section{Results and Discussions}

The results from 3 different dentistry operation lights are obtained, which include 2 dentistry operation lights with LED source and one with filament source. The Figure 2 presents the normalized spectral irradiance for the measured equipment.

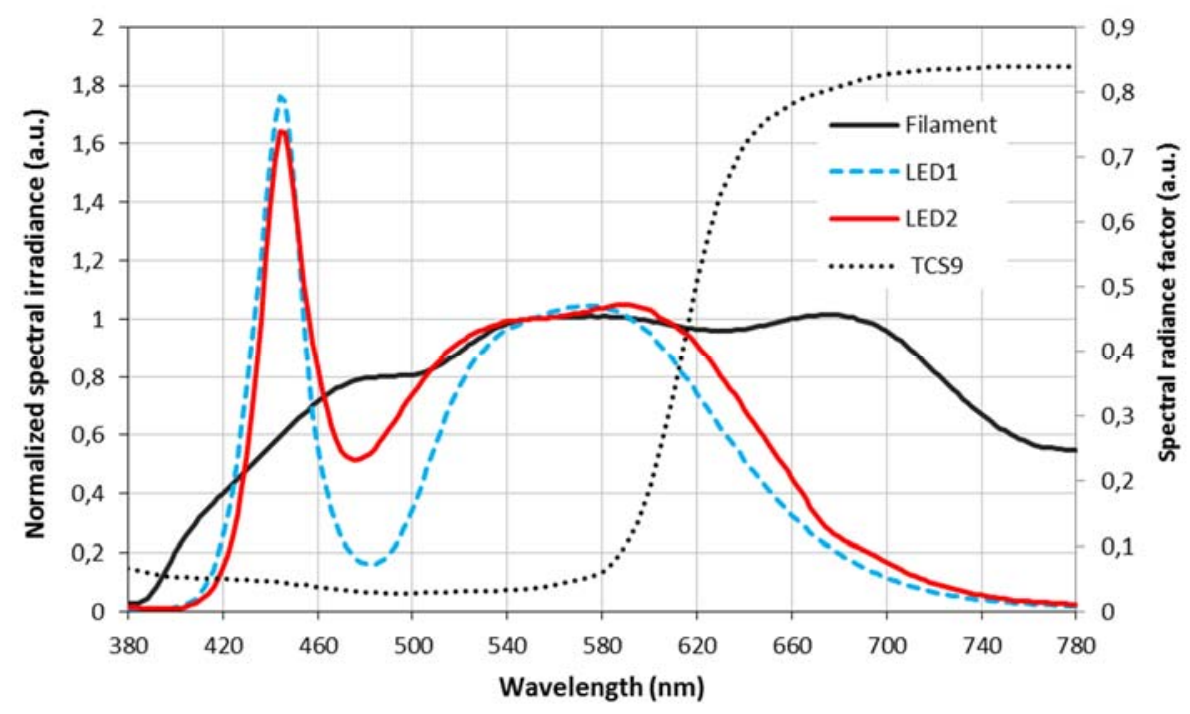

Figure 2 - Normalized spectral irradiance at $550 \mathrm{~nm}$ (right side). Spectral radiance factor for test colour sample 9 (TCS9) from CIE 13.3:1995 (left side). 
The filament source type spectral irradiance distribution does not match the shape of an illuminant $A$ which is mainly associated to head reduction elements included in the equipment optics. The LED source type spectral irradiance distribution presents the maximum irradiance in blue part of spectrum.

The general colour rendering index $\left(R_{\mathrm{a}}\right)$, special rendering index number $9\left(R_{9}\right)$, correlated colour temperature (CCT) and the corresponding ISO 9680:2014 limits for all dentistry operation light are presented in Table 1 . The measured chromaticity coordinates and its limits are presented in Figure 3.

Table 1 - Measured colour rendering index and the ISO 9680:2014 limits for dentistry operation light.

\begin{tabular}{|c|c|c|c|c|}
\hline & \multirow{2}{*}{$\begin{array}{c}\text { Limits of } \\
\text { ISO 9680:2014 }\end{array}$} & Filament & LED1 & LED2 \\
\cline { 3 - 5 } & $4500 \mathrm{~K}$ to $6400 \mathrm{~K}$ & 4400 & 4995 & 5165 \\
\hline CCT (K) & $>85$ & 94,5 & 72,3 & 87 \\
\hline $\boldsymbol{R}_{\mathrm{a}}$ & - & 77,1 & $-16,0$ & 32,2 \\
\hline $\boldsymbol{R}_{\mathbf{9}}$ & & & & \\
\hline
\end{tabular}

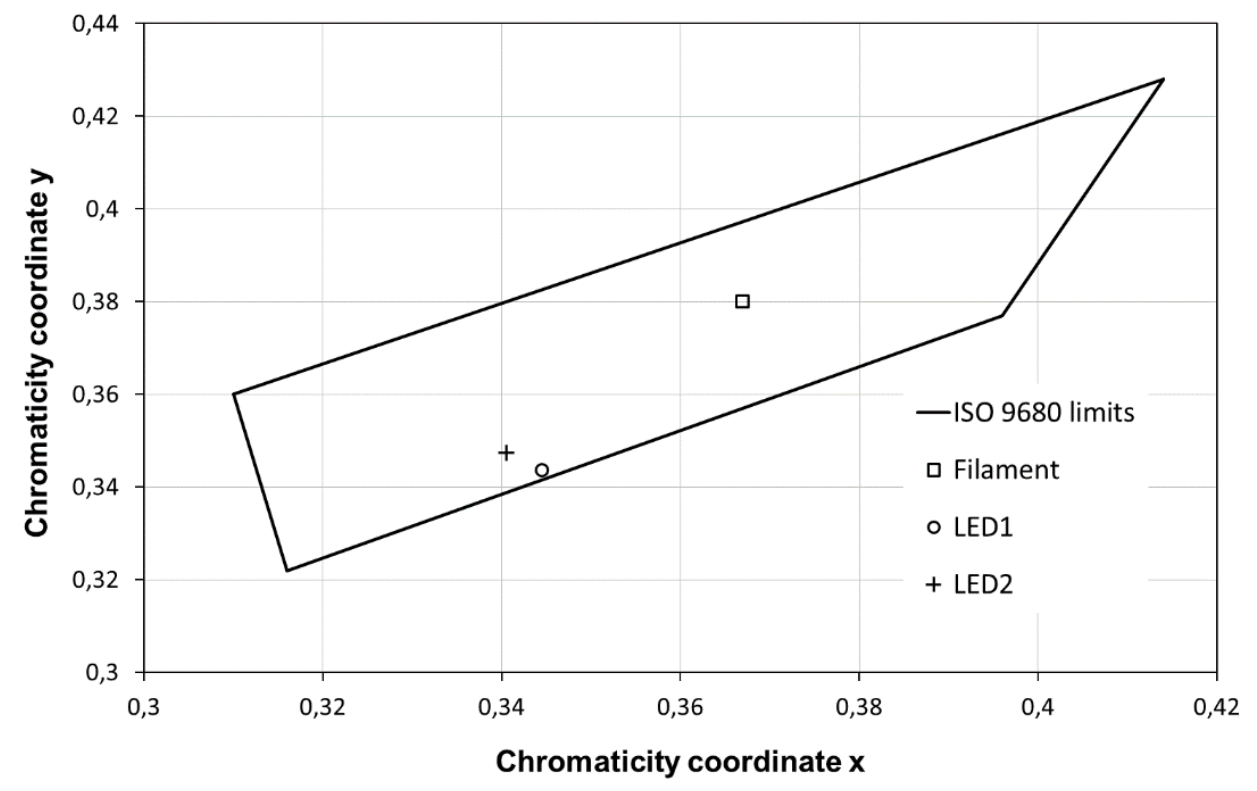

Figure 3 - Measured chromaticity coordinates and its ISO 9680:2014 limits.

The CCT limit presented in Table 1 is only a recommendation for dentistry operation light. The major restriction for colour is the chromaticity area (ISO, 2014) indicated in the Figure 3 . It is possible to note that all equipment accomplish with the limits of chromaticity, however this does not occur to $R_{\text {a }}$ limits in Table 1 . The ISO 9680 does not state limits for $R_{9}$, but this is one of test colour samples that cause more problem in CRI calculation due to intense light emission of LEDs in the blue part of spectrum. In some case, the $R_{9}$ can be negative as presented in Table 1. The spectral radiance factor for test colour sample 9 (TCS9) used to calculated $R_{9}$ is presented in the Figure 2 to show that the LED intense emission occurs in the spectral range that TCS9 has the lower spectral radiance factor which can cause wide colour shift in comparison to illuminat A. Despite of ISO 9680:2014 excludes dentistry operation light using LED sources from $R$ a requirements, the results in Table 1 shows that equipment using LED sources can fulfil the $R$ a. 


\section{Conclusions}

The majority of general colour rendering index obtained from the evaluated dentistry operation lights are above the ISO 9680:2014 requirement of $R a>85$. The chromaticity coordinate of LED1 is at the border limit of ISO 9680:2014 requirement, but far enough for equipment conformity to the standard.

Although the ISO 9680:2014 excludes LED light source from the general colour rendering index requirement it is observed that there are dentistry operation lights in the market fulfilling this standard requirement.

\section{References}

ASTM 2012. ASTM G138:2012. Standard Test Method for Calibration of a Spectroradiometer Using a Standard Source of Irradiance. West Conshohocken: ASTM.

CIE 1984. CIE 63:1984. The Spectroradiometric Measurement of Light Sources. Vienna: CIE.

CIE 1995. CIE 13.3-1995. Method of Measuring and Specifying Colour Rendering Properties of Light Sources. Vienna: CIE.

CIE 2007. CIE 177:2007. Colour Rendering of White LED Light Sources. Vienna: CIE.

CIE 2017. CIE 224:2017. Colour Fidelity Index for accurate scientific use. Vienna: CIE.

GUO, X., HOUSER, K. W. 2004. A review of colour rendering indices and their application to commercial light sources. Lighting Research \& Technology, 36(3), 183-197.

IEC 2013. IEC 60601-2-41 Ed. 2.1:2013 Medical electrical equipment - Part 2-41: Particular requirements for the basic safety and essential performance of surgical luminaires and luminaires for diagnosis. Geneva: IEC.

ISO 2014. ISO 9680:2014. Dentistry - Operating lights. Geneva: ISO.

SÁNDOR, N., BODROGI, P., CSUTI, P., KRÁNICZ, B., SCHANDA, J. 2003. Direct visual assessment of colour rendering. In Proc. 25th CIE Session. CIE 152:2003, D1-42.

SÁNDOR, N., SCHANDA, J. 2006. Visual colour rendering based on colour difference evaluations. Lighting Research \& Technology, 38(3), 225-239.

Note: Specific firms and trade names are identified in this paper to describe the experimental procedure adequately. Such identification does not imply recommendation or endorsement by the author, nor does it imply that the materials or equipment identified are necessarily the best available for the purpose. 